\title{
Indissociabilidade do ensino, pesquisa e extensão na prática profissional do ensino médio integrado à educação profissional
}

\author{
Maristela Beck Marques \\ Instituto Federal de Educação, Ciência e Tecnologia Farroupilha (IFFAR) - Campus Santa Rosa \\ (maristela.marques@iffarroupilha.edu.br) \\ Josimar de Aparecido Vieira \\ Instituto Federal do Rio Grande do Sul (IFRS) - Campus Sertão \\ (josimar.vieira@sertao.ifrs.edu.br)
}

\begin{abstract}
Resumo: Este trabalho é parte integrante de uma pesquisa em andamento relacionada a um curso de mestrado profissional que aborda a Educação Profissional e Tecnológica (EPT). Buscou-se analisar procedimentos que estão sendo utilizados na implementação da prática profissional no ensino médio integrado à educação profissional (EMIEP), com a finalidade de promover a indissociabilidade entre o ensino, pesquisa e extensão na formação do estudante. Constituído numa abordagem qualitativa, foi produzido por meio da análise de diretrizes e perspectivas da prática profissional neste nível e modalidade de ensino no Instituto Federal de Educação, Ciência e Tecnologia Farroupilha (IFFar) - Campus Santa Rosa, bem como das normativas relacionadas a indissociabilidade do ensino, pesquisa e extensão contida em documentos institucionais e de pesquisa bibliográfica concentrada em obras de autores que investigam a citada temática. As repercussões indicam que a prática profissional prevista na estruturação do percurso formativo do estudante de educação profissional, organizadas intencionalmente nos currículos dos cursos, representam a possibilidade de efetivar na educação básica a indissociabilidade da tríade ensino, pesquisa e extensão. O compromisso de educação integral expresso nos documentos dos Institutos Federais encontram nas orientações da citada indissociabilidade possibilidades concretas de efetivação desta missão. É nesta lógica que o IFFar propõe nas suas diretrizes a Prática Profissional Integrada (PPI), prevista nos projetos pedagógicos dos cursos, onde indica possibilidade de ação curricular, constituindo oportunidade de construção de metodologia integradora, compatível com os princípios da interdisciplinaridade, da contextualização e da integração entre teoria e prática no processo ensino-aprendizagem, podendo potencializar a relação entre educação e prática social, entre pesquisa e o princípio educativo do trabalho.
\end{abstract}

Palavras-chave: Educação profissional e tecnológica; Ensino, pesquisa e extensão; Prática profissional

\section{Inseparability of teaching, research and extension in high school professional practice integrated with vocational education}

Abstract: This work is an integral part of ongoing research related to a professional master's course that addresses Vocational and Technological Education (EFA). We sought to analyze procedures that are being used in the implementation of professional practice in high school integrated to vocational education (EMIEP), with the purpose of promoting the indissociability between teaching, research and extension in student education. Constituted in a qualitative approach, it was produced through the analysis of guidelines and perspectives of professional practice at this level and modality of teaching at the Federal Institute of Education, Science and Technology Farroupilha (IFFar) - Campus Santa Rosa, as well as the norms related to the indissociability of teaching, research and extension contained in institutional documents and bibliographic research concentrated on works by authors who investigate the aforementioned theme. The repercussions indicate that the professional practice foreseen in the structuring of the formative path of the professional education student, intentionally organized in the curriculum of the courses, represents the possibility of making effective in basic education the inseparability of the teaching, research and extension triad. The commitment of integral education expressed in the documents of the Federal Institutes find in the orientations of the aforementioned inseparability concrete possibilities of accomplishing this mission. It is in this logic that IFFar proposes in its guidelines the Integrated Professional Practice (PPI), foreseen in the pedagogical projects of the courses, which indicates the possibility of curricular action, providing the opportunity to build an integrative methodology, compatible with the principles of interdisciplinarity, 
contextualization and the integration between theory and practice in the teaching-learning process, which may enhance the relationship between education and social practice, between research and the educational principle of work.

Keywords: Professional and technological education; Teaching, research and extension; Professional practice

\section{INTRODUÇÃO}

O estabelecimento das dimensões ensino, pesquisa e extensão na educação superior em Universidades está previsto na Constituição Federal de 1988 em seu Art 207 "As universidades gozam de autonomia didático-científica, administrativa e de gestão financeira e patrimonial, e obedecerão ao princípio de indissociabilidade entre ensino, pesquisa e extensão (BRASIL, 2019, p. 160). No Capítulo IV da Lei de Diretrizes e Bases da Educação Nacional de 1996, ao tratar da educação superior, em vários momentos é destacado o ensino, a pesquisa e extensão como dimensões responsáveis pela criação cultural e o desenvolvimento do espírito científico e do pensamento reflexivo.

A Lei n ${ }^{0} 11.892$, de 29 de dezembro de 2008 dispõe que os Institutos Federais de Educação, Ciência e Tecnologia (IFs) são Instituições de Educação Superior, básica e profissional, pluricurriculares e multicampi, especializados na oferta de educação profissional e tecnológica nas diferentes modalidades de ensino, com base na conjugação de conhecimentos técnicos e tecnológicos com as suas práticas pedagógicas, equiparando-se às universidades federais para efeitos regulatórios.

Nesta direção, este trabalho tem a finalidade de analisar a perspectiva da indissociabilidade do ensino, pesquisa e extensão nos IFs, mais especificamente no ensino médio integrado à educação profissional (EMIEP). Ele faz parte de uma investigação ampliada que está sendo desenvolvida no curso de Mestrado Profissional em Educação Profissional e Tecnológica do Programa de PósGraduação em Educação Profissional e Tecnológica (ProfEPT). Trata-se de um trabalho de pesquisa onde estão envolvidos os cursos Técnico em Móveis e Técnico em Edificações que são integrados ao ensino médio e oferecidos pelo Instituto Federal de Educação, Ciência e Tecnologia Farroupilha (FFFar) - Campus Santa Rosa. Nesta investigação ampliada está sendo analisado procedimentos que estão sendo utilizados na implementação da prática profissional no ensino médio integrado 
à educação profissional, com a finalidade de promover a indissociabilidade entre o ensino, pesquisa e extensão na formação do estudante.

Considerando que esta pretensão é abrangente, a produção deste estudo se concentrou na compreensão das seguinte questões: qual a perspectiva das dimensões ensino, pesquisa e extensão a serem desenvolvidas de forma indissociável nos cursos técnicos de nível médio nos IFs? Quais as orientações contidas nos documentos institucionais do IFFar a respeito do tema? E finalmente, como está sistematizada a proposta metodológica organizada pelo IFFar denominada Prática Profissional Integrada (PPI) organizada no sentido de efetivar esta intenção.

[...] a concepção de Educação Profissional e Tecnológica (EPT) orienta os processos de formação com base nas premissas da integração e da articulação entre ciência, tecnologia, cultura e conhecimentos específicos e do desenvolvimento da capacidade de investigação científica como dimensões essenciais à manutenção da autonomia e dos saberes necessários ao permanente exercício da laboralidade, que se traduzem nas ações de ensino, pesquisa e extensão (BRASIL, 2010, p. 26 grifo nosso).

O EMIEP oferecido nos IFs surgem como proposição de um compromisso de ruptura às formas conservadoras de organização da Educação Profissional e Tecnológica (EPT), expressando uma concepção de formação humana, com base na integração de todas as dimensões da vida no processo educativo, visando à formação omnilateral dos sujeitos.

Como formação humana, o que se busca é garantir ao adolescente, ao jovem e ao adulto trabalhador o direito a uma formação completa para a leitura do mundo e para a atuação como cidadão pertencente a um país, integrado dignamente à sua sociedade política. Formação que, nesse sentido, supõe a compreensão das relações sociais subjacentes a todos os fenômenos (Ciavatta, 2005, p. 85).

Para a efetivação desta proposta há a necessidade de superar a dualidade existente entre o oferecimento de educação profissional e de ensino médio, construindo um projeto unitário de ensino médio, envolvendo currículo, princípios, conteúdo e forma.

O conceito de integração entretanto, vai além da forma. Não se trata de somar os currículos e/ou as cargas horárias referentes ao ensino médio e às habilitações profissionais, mas sim de relacionar, internamente à organização curricular e do desenvolvimento do processo de ensino-aprendizagem, conhecimentos gerais e específicos; cultura e trabalho; humanismo e tecnologia. A 
construção destas relações tem como mediações o trabalho, a produção do conhecimento científico e da cultura (RAMOS, 2010, p. $51)$.

Do ponto de vista organizacional, essa relação deve integrar em um mesmo currículo a formação plena do educando, possibilitando construções intelectuais elevadas; a apropriação de conceitos necessários para a intervenção consciente na realidade e a compreensão do processo histórico de construção do conhecimento (BRASIL,2007, p.47 grifo nosso).

Considerando que o ensino, a pesquisa e a extensão, num sentido de desenvolvimento indissociável traduzem este compromisso, a efetivação destas ações contribuiriam para que se concretize a formação integral.

Cumpre salientar a importância de espaços de ações didático-pedagógicas organizados intencionalmente para que as finalidades a que se propõem um projeto se concretizem.

É necessário enfrentar também o desafio de pensar estratégias de organização curricular e de ensino que favoreçam a superação da visão fragmentária e linear da realidade e tornem mais possível um projeto de formação orientado pela ideia de integração (ARAUJO; FRIGOTTO, 2015, p. 70).

É nesta lógica que o IFFar propõe nas suas diretrizes a Prática Profissional Integrada (PPI), prevista nos projetos pedagógicos dos cursos do IFFar, indicando a possibilidade de ação curricular, constituindo em oportunidade de construção de metodologia integradora, compatível com os princípios da interdisciplinaridade, da contextualização e da integração entre teoria e prática no processo ensinoaprendizagem, podendo potencializar a relação entre educação e prática social, entre pesquisa e o princípio educativo do trabalho efetivando assim a indissociabilidade entre ensino, pesquisa e extensão.

Diante dessas considerações, este trabalho está organizado em três seções, conforme segue: inicia apresentando princípios de ensino, pesquisa e extensão presentes nas normativas educacionais; segue relatando como se apresentam esta questão nos documentos do IFFar; aponta a PPI como possibilidade de organização curricular; sendo apresentados caminhos para a implementação da prática profissional na perspectiva da indissociabilidade da tríade ensino, pesquisa e extensão, apresentando uma síntese conclusiva deste estudo que está em andamento 


\section{MATERIAIS E MÉTODOS}

Constituído numa abordagem qualitativa, este estudo foi produzido por meio da análise de dados que se encontram disponibilizados em documentos institucionais e referências bibliográficas envolvendo os autores: Ciavatta (2005), Ramos (2010), Araújo; Frigotto (2015), Machado (2010) Rays (2003), Pacheco (2011), Sobrinho (2017). A análise documental incluiu documentos normativos orientadores relacionados ao EMIEP do IFFar, examinando de que forma estão organizadas e disciplinadas as ações relacionadas com a indissociabilidade das dimensões do ensino, pesquisa e extensão no nível médio. Analisou-se as concepções e diretrizes dos IFs que foi publicado pelo Ministério de Educação em 2010, onde encontra-se explicitada a intenção dos IFs, o Plano de Desenvolvimento Institucional (PDI) do IFFar - 2019-2026, o Projeto Pedagógico Institucional (PPI) do IFFar e as Diretrizes dos Cursos Técnicos do IFFar - 2019, pelo entendimento que estes documentos orientam a construção e o desenvolvimento do Projetos Pedagógicos de Cursos (PPCs), onde são encontradas a organização e a efetivação didático pedagógico de cada curso.

Analisou-se as concepções e diretrizes dos IFs publicação realizada em 2010, pelo Ministério de Educação, onde explicita-se a intenção dessas instituições, o Plano de Desenvolvimento Institucional (PDI) do IFFar - 2019-2026, o Projeto Pedagógico Institucional (PPI) do IFFar e as Diretrizes dos Cursos Técnicos do IFFar - 2019, pelo entendimento de que estes documentos orientam a construção e o desenvolvimento dos Projetos Pedagógicos de Cursos (PPCs), onde são encontradas a organização e a efetivação didático pedagógico de cada curso.

\section{RESULTADOS}

Os resultados apresentados neste trabalho se constitui basicamente de análise documental e mais especificamente de normativas referente ao tema.

Observa-se que a indissociabilidade do ensino, pesquisa e extensão no EMIEP é manifestada por força da verticalização do ensino proposta no projeto educativo dos IFs. 
Embora o termo extensão esteja relacionado a educação superior, é possível relacionar por meio de definições, princípios e intencionalidade às diretrizes previstas para a educação profissional técnica de nível médio.

O compromisso de educação integral expresso nos documentos encontra nas orientações da indissociabilidade da tríade ensino, pesquisa e extensão possibilidades concretas de efetivação desta missão.

A proposta do IFFar, de organização da Prática Profissional, como metodologia integradora aponta a perspectiva de ação didática, indutora de superação da fragmentação do conhecimento indicando perspectivas concretas do trabalho envolvendo o ensino, pesquisa e extensão.

O fazer pedagógico desses institutos, ao trabalhar na superação da separação ciência/tecnologia e teoria/prática, na pesquisa como princípio educativo e científico, nas ações de extensão como forma de diálogo permanente com a sociedade, revela sua decisão de romper com um formato consagrado, por séculos, de lidar com o conhecimento de forma fragmentada (Pacheco, 2010, p. 27).

\section{DISCUSSÃO}

\section{Ensino-pesquisa e extensão no ensino médio}

Encontramos nos documentos normativos com relação ao ensino médio, orientações, utilizando a denominação ensino e pesquisa, no entanto com relação a extensão faz-se necessário a associação da intenção ao termo, que ao ser manifesto nas normas educacionais num sentido amplo, refere-se à educação superior.

Na Lei de Diretrizes e Bases (LDB), lei 9394 de 1996, que estabelece as diretrizes e bases da educação nacional, o uso do termo "extensão" restringe-se ao capítulo IV "Da educação superior".

Partiremos do conceito de extensão universitária, definido pelo Fórum dos pró-reitores das universidades (FORPROEX), explicitando em 1987 como uma práxis educativa, embasado no princípio de indissociabilidade.

A Extensão Universitária é o processo educativo, cultural e científico que articula o Ensino com a Pesquisa de forma indissociável e viabiliza a relação transformadora entre Universidade e Sociedade. A Extensão é uma via de mão-dupla, 
com trânsito assegurado à comunidade acadêmica, que encontrará, na sociedade, a oportunidade de colaboração da práxis de um conhecimento acadêmico. No retomo à Universidade, docentes e discentes trarão um aprendizado que, submetido à reflexão teórica, será acrescido àquele conhecimento. Esse fluxo, que estabelece a troca de saberes sistematizados, acadêmico e popular, terá como consequências a produção do conhecimento resultante do confronto com a realidade brasileira e regional, a democratização do conhecimento acadêmico com a participação efetiva da comunidade na atuação da Universidade. Além de instrumentalizadora deste processo dialético de teoria/prática, a Extensão é um trabalho interdisciplinar que favorece a visão integrada do social (BRASIL, 2006, p. 21. Grifo nosso).

Podemos inserir que a indissociabilidade é princípio que manifesta a intenção de busca de unidade de teoria e prática, buscando o rompimento do formato tradicional de segmentação e separação de ações pedagógicas.

[...] se entendemos a indissociabilidade como ato processual que traz em si a marca da omnilateralidade em devir, ela não terá outra função se não a de promover o processamento da interatividade crítica que rompe, por sua vez, com a cultura dissociativa entre o ensino, a pesquisa e a extensão (RAYS, 2003, p .1).

Nas orientações contidas nos documentos e pareceres emitidos pelo Conselho Nacional de Educação e Ministério de Educação, os eixos norteadores da construção e efetivação do currículo na Educação Básica no Brasil são o trabalho como princípio educativo e a pesquisa como princípio pedagógico, evidenciando que devem estar presentes em toda a Educação Básica e, de modo especial no EMIEP, em todas as suas formas de oferta e de organização.

A pesquisa como princípio pedagógico propõe um rompimento com o formato de uma educação alicerçada no conceito de transmissão de conteúdos, na direção de um paradigma de articulação entre o conhecimento, o protagonismo e a prática social explicitada a intenção no parecer do Conselho Nacional de Educação (CNE)/Câmara de Educação Básica (CEB), que trata das Diretrizes Curriculares Nacionais para a Educação Profissional Técnica de Nível Médio.

Para tanto, a Educação Profissional Técnica de Nível Médio deve ser concebida como oportunidade para a formação humana integral, tendo como eixo estruturante a integração entre trabalho, ciência, tecnologia e cultura, fundamentando-se no trabalho como princípio educativo, na pesquisa como princípio pedagógico e na permanente articulação com o desenvolvimento socioeconômico, para garantir ao cidadão trabalhador a oportunidade de exercer sua cidadania com dignidade e justiça social (BRASIL, 2012a, p. 38). 
O parecer citado deu origem a Resolução $N^{\circ} 6$, de 20 de setembro de 2012, que Define Diretrizes Curriculares Nacionais para a Educação Profissional Técnica de Nível Médio, onde no capítulo que trata dos princípios norteadores da Educação Profissional Técnica de Nível Médio reitera a indicação de assumir a pesquisa como princípio pedagógico e o trabalho como princípio educativo.

Art. $6^{\circ}$ São princípios da Educação Profissional Técnica de Nível Médio:

(.....)

III - trabalho assumido como princípio educativo, tendo sua integração com a ciência, a tecnologia e a cultura como base da proposta político-pedagógica e do desenvolvimento curricular;

(...)

IV - articulação da Educação Básica com a Educação Profissional e Tecnológica, na perspectiva da integração entre saberes específicos para a produção do conhecimento e a intervenção social, assumindo a pesquisa como princípio pedagógico (BRASIL, 2012b, p. 2, grifo nosso).

A pesquisa assumida como princípio pedagógico, educativo, promove o questionamento constante, potencializado pela atitude de leitura crítica da realidade, da capacidade de produzir reflexivamente o conhecimento rompendo com um paradigma de ensino conservador que transfere e reproduz conhecimentos de forma fragmentária.

A relação entre teoria e prática se impõe, assim, não apenas como princípio metodológico inerente ao ato de planejar as ações, mas, fundamentalmente, como princípio epistemológico, isto é, princípio orientador do modo como se compreende a ação humana de conhecer uma determinada realidade e intervir sobre ela no sentido de transformá-la. A unidade entre pensamento e ação está na base da capacidade humana de produzir sua existência. É na atividade orientada pela mediação entre pensamento e ação que se produzem as mais diversas práticas que compõem a produção de nossa vida material e imaterial: o trabalho, a ciência, a tecnologia e a cultura (BRASIL, 2012.a, p. 16).

$\mathrm{Na}$ orientação contida nas diretrizes, podemos relacionar a intencionalidade "produção do conhecimento e a intervenção social", como a indicação de ensino, pesquisa e extensão serem desenvolvidas de forma articulada e indissociável no EMIEP. Presume-se, portanto, que a viabilidade de efetivar a interdisciplinaridade e a visão integrada a que se refere os conceitos dependerá das opções e organizações do currículo escolar, tanto da universidade como na educação básica, sendo que as atividades podem ser realizadas em tempos e espaços distintos ou se efetivarem imbricadas nas práticas de ensino de pesquisa e de extensão. 


\section{A indissociabilidade do ensino-pesquisa e extensão nos Institutos Federais}

Os IFs foram criados pela Lei $n^{0} 11.892$, de 29 de dezembro de 2008, com a intenção de propor um novo modelo de instituição de educação profissional e tecnológica, sendo estruturados a partir dos Centro Federais de Educação Tecnológica (Cefet), Escolas Técnicas Federais, Agrotécnicas e vinculadas às Universidades Federais, conforme consta no documento de "Um novo modelo em educação profissional e tecnológica" que aponta as Diretrizes e Concepções desta nova Instituição.

O foco dos Institutos Federais será a justiça social, a equidade, a competitividade econômica e a geração de novas tecnologias. Responderão, de forma ágil e eficaz, às demandas crescentes por formação profissional, por difusão de conhecimentos científicos e tecnológicos e de suporte aos arranjos produtivos locais. Os novos Institutos Federais atuarão em todos os níveis e modalidades da educação profissional, com estreito compromisso com 0 desenvolvimento integral do cidadão trabalhador (BRASIL, 2010, p. 2).

Os IFs trazem para a Educação básica, no caso o nível médio, o termo extensão, até então encontradas nas normativas relacionadas à educação superior, reforçando neste sentido a intenção manifesta nas diretrizes para a educação básica e para a educação profissional técnica de nível médio quanto aos princípios que regem esta oferta educacional.

O desafio colocado para os Institutos Federais no campo da pesquisa é, pois, ir além da descoberta científica. Em seu compromisso com a humanidade, a pesquisa, que deve estar presente em todo o trajeto da formação do trabalhador, deve representar a conjugação do saber e de mudar e se construir, na indissociabilidade da pesquisa, ensino e extensão. E mais: os novos conhecimentos produzidos pelas pesquisas deverão estar colocados a favor dos processos locais e regionais numa perspectiva de seu reconhecimento e valorização no plano nacional e global (BRASIL, 2010, p. 35).

\section{A tríade indissociável no IFFar}

O Plano de Desenvolvimento Institucional (PDI) do IFFar, construído com a participação de toda a comunidade acadêmica, é o documento da Instituição que descreve a filosofia de trabalho, a missão a que se propõe, as diretrizes pedagógicas que orientam as suas ações, a sua estrutura organizacional e as atividades 
acadêmicas que desenvolve e/ou que pretende desenvolver, neste plano está contido o Projeto Pedagógico Institucional (PPI) traduzindo a proposta pedagógica do IFFar, apresentando sua contextualização, fundamentos, princípios, políticas, prioridades e planejamento, no que diz respeito ao ensino, à pesquisa e à extensão. Os objetivos, as metas e as ações fixadas no documento analisado terão vigência no período de 2019 a 2026.

No ensino médio integrado, a formação geral do estudante deve se tornar inseparável da formação profissional, que deve enfocar o trabalho como princípio educativo, objetivando superar a dicotomia entre trabalho manual e trabalho intelectual e a compreensão dos fundamentos científico-tecnológicos dos processos produtivos, relacionando a teoria com a prática, no ensino de cada componente curricular (IFFar,2019 a, p. 50).

O PPI (2019-2026) aponta que as ações de ensino, pesquisa e extensão, tendo a possibilidade de acontecerem em tempos e espaços distintos, tem a premissa de terem como eixo fundamental: "[...] a função social [...] de democratizar - saber e contribuir para a construção de uma sociedade ética e solidária", ressaltando o compromisso legal dos IFs. Descreve a extensão no IFFar (IFFar, 2019a, p. 62) “[...] como um processo educativo, cultural, social, científico e tecnológico que promove a interação transformadora entre as instituições, os segmentos sociais e o mundo do trabalho local e regional”.

$\mathrm{Na}$ relação ensino, pesquisa e extensão, amplia-se o conceito de aula para além do tempo formal na instituição, para todo tempo e espaço, dentro ou fora da instituição. Assim, a pesquisa e a extensão configuram-se como princípios educativos em cursos de todos os níveis e modalidades. Por isso, devem constituir-se em trabalho específico e sistemático em resposta às necessidades que emergem na articulação entre o currículo e os anseios da comunidade (IFFar,2019 a, p. 54).

No item "Políticas de Pesquisa, Extensão, Empreendedorismo e Inovação" a indissociabilidade entre ensino, pesquisa e extensão aparece como um dos princípios e objetivos:

Indissociabilidade entre Ensino, Pesquisa e Extensão pressupõe-se neste princípio que as ações de extensão adquirem maior efetividade se estiverem vinculadas ao processo de formação de pessoas (Ensino) e de geração de conhecimento (Pesquisa). $\mathrm{Na}$ relação Extensão-Ensino, a diretriz de indissociabilidade coloca o estudante como protagonista de suas formações técnica e cidadã. $\mathrm{Na}$ relação Extensão- Pesquisa, visando à produção de conhecimento, a Extensão Universitária sustenta-se principalmente em metodologias participativas, no formato Impacto na formação do 
estudante. Para imprimir qualidade à formação do estudante e promover o protagonismo estudantil, as ações extensionistas devem explicitar três elementos essenciais: (I) a designação do orientador; (II) os objetivos da ação e as competências dos atores nela envolvidos; (III) a metodologia de avaliação da participação do estudante. A articulação destas ações com a formação do estudante depende, também, de um diálogo franco e permanente dos órgãos destinados ao fomento das ações extensionistas com os colegiados de gestão acadêmica dos cursos (IFFar, 2019a, p. 63).

\section{A prática profissional como possibilidade de promover a indissociabilidade das dimensões do ensino, pesquisa e extensão}

A Prática profissional está prevista na estruturação do percurso formativo do estudante de Educação Profissional, sendo que nas orientações de organização são apresentadas referências quanto a intencionalidade desta ação.

[...] a prática se configura não apenas como situações ou momentos distintos de um curso, mas como inerente a uma metodologia de ensino que contextualiza e põe em ação todo o aprendizado. [...] Neste contexto, o estágio profissional supervisionado, obrigatório ou não, quando previsto e assumido intencionalmente pela escola como ato educativo e atividade curricular de sua responsabilidade, presente na sua proposta pedagógica e nos instrumentos de planejamento curricular do curso, é uma das estratégias de integração teórico-prática, intencionalmente integrada com o currículo do curso (BRASIL, 2012a, p. 48-49).

Assim sendo, o IFFar, de novembro de 2012 a dezembro de 2013, conforme relato de Sidinei Cruz Sobrinho, passou por um processo de debate e elaboração de um documento institucional que descrevesse as diretrizes para o EMIEP na Instituição. Esta reorganização busca possibilidades de efetivar com maior qualidade - EMIEP, considerando os pressupostos que regem a concepção deste nível e modalidade de ensino (SOBRINHO, 2017).

Sobrinho (2017, p. 106) destaca que "A integração, em si, não se dá e não está na forma de organização do currículo, mas no processo de ensino e de aprendizagem que se dá a partir dele", ressaltando que para evitar que o currículo integrado, previsto nos PPCs, não corra o risco de transformar-se em uma formalidade curricular, é necessário pensar e propor metodologias de ensino e de aprendizagens, bem como ações para realizar o movimento interdisciplinar. 
Nesta organização foi reorganizado o espaço pedagógico denominado Prática Profissional Integrada (PPI), que se traduz numa "[...] estratégia educacional favorável para a contextualização, a flexibilização e a integração curricular" (SOBRINHO, 2017, p. 129).

A Pratica Profissional Integrada está normatizada atualmente pela resolução $N^{\circ}$ 028/2019, de 07 de agosto de 2019, onde encontramos as "Diretrizes administrativas e curriculares para a organização didático-pedagógica da educação profissional técnica de nível médio no Instituto Federal de educação, ciência e tecnologia Farroupilha", a PPI é colocada como metodologia prevista na organização curricular dos cursos técnicos do IFFar, em todas as formas e modalidades.

Art. 103 São objetivos específicos das PPIs:

II - aproximar a formação dos estudantes com o mundo de trabalho;

VI - assegurar espaço destinado ao enfoque para a formação do perfil profissional do egresso desejado pelo curso, bem como contemplar as especificidades da localização geográfica que se encontra e as particularidades regionais;

VIII - incentivar a pesquisa como princípio educativo;

IX - integrar o trabalho manual com o trabalho intelectual;

$X$ - promover a interdisciplinaridade;

$\mathrm{XI}$ - promover a indissociabilidade entre ensino, pesquisa e extensão;

XII - incentivar a inovação tecnológica.

Art. 108. A PPI é uma metodologia de ensino que contextualiza a aplicabilidade dos conhecimentos aprendidos no decorrer do processo formativo, problematizando a realidade, fazendo com que os estudantes, por meio de estudos, pesquisas e práticas desenvolvam projetos e ações, baseados na criticidade e na criatividade.

Art. 109. A PPI é um dos espaços no qual se busca formas e métodos responsáveis por promover, durante todo o itinerário formativo, a politecnia, formação integral, omnilateral, interdisciplinaridade, integrando os núcleos da organização curricular (IFFar, 2019b, p. 28).

A organização da PPI prevê: no mínimo 5\% da carga horária das disciplinas destinada à realização de PPI, distribuída entre todas as etapas de realização do curso, ou $10 \%$ da carga horária das disciplinas do curso caso não tenha previsão de TCC e/ou Estágio Curricular Supervisionado Obrigatório, nos cursos na EJA/EPT (Proeja) será desenvolvida no Projeto Integrador e não necessita seguir este percentual. 
O planejamento da PPI se dá preferencialmente antes do semestre letivo e o início do desenvolvimento até 20 dias após o primeiro dia letivo.

I - Planejamento coletivo com o colegiado do curso para elaboração do projeto de PPI e definição de quais disciplinas integrarão, diretamente, este projeto:

a) nos cursos técnicos integrados, serão envolvidas diretamente, em cada projeto de PPI, no mínimo, quatro (04) disciplinas contemplando, necessariamente, disciplinas da área básica e da área técnica, independente da organização em núcleos na matriz curricular;

b) nos cursos técnicos subsequentes, serão envolvidas diretamente, em cada projeto de PPI, no mínimo duas disciplinas ((IFFar, 2019b, p. 29).

Quanto aos registros da metodologia há a indicação:

Art. 115. O registro das atividades de PPI será realizado no diário de classe de cada disciplina indicada no projeto de PPI, conforme a carga horária específica.

Parágrafo único. A carga horária específica de PPI para cada disciplina integra o cômputo da carga horária total da disciplina prevista na matriz curricular.

Art. 119. O projeto de PPI deverá ser anexado aos Planos de Ensino das disciplinas envolvidas no Sistema Integrado de Gestão das Atividades Acadêmicas (SIGAA) (IFFar, 2019b, p. 30).

Observa-se a preocupação institucional de normatizar e acompanhar esta metodologia de currículo, por meio de orientações complementares e acompanhamento do planejamento e execução.

\section{CONSIDERAÇÕES FINAIS}

A análise dos documentos normativos nos permite inserir que as diretrizes em relação ao ensino, pesquisa e extensão nos IFs e especificamente no IFfar, trazem em si, o conceito de práxis educativa, embasado no princípio de indissociabilidade.

Nesta direção, reafirmando o sentido indissociável das ações da educação diante da realidade, encontramos em Freire (1983), na obra extensão ou comunicação, a importância da tomada de consciência da realidade na qual e com a qual estão e com isto reconhecer-se como parte desta realidade, transformando-a, construindo o conhecimento. 
Estamos convencidos de que, qualquer esforço de educação popular, esteja ou não associado a uma capacitação profissional, seja no campo agrícola ou no industrial urbano, deve ter, pelas razões até agora analisadas, um objetivo fundamental: através da problematização do homem-mundo ou do homem em suas relações com o mundo e com os homens, possibilitar que estes aprofundem sua tomada de consciência da realidade na qual e com a qual estão. Este aprofundamento da tomada de consciência, que precisa desdobrar-se na ação transformadora da realidade, provoca, com esta ação, a superação do conhecimento preponderantemente sensível daquela com que se alcança a razão da mesma. É uma apropriação que faz o homem da posição que ocupa no seu aqui e no seu agora, do que resulta (e ao mesmo tempo produz) o descobrir-se em uma totalidade, em uma estrutura, e não "preso", ou "aderido" a ela ou às partes que a constituem. Ao não perceber a realidade como totalidade, na qual se encontram as partes em processo de interação, se perde o homem na visão "focalista" da mesma. A percepção parcializada da realidade rouba ao homem a possibilidade de uma ação autêntica sobre ela (FREIRE, 1983, p. 22).

Espera-se que o presente trabalho, por suas limitações, estimule novas investigações e contribua para uma reflexão maior sobre a indissociabilidade do ensino, pesquisa e extensão na prática profissional do EMIEP. Além disso, deve possibilitar um repensar dos projetos pedagógicos dos cursos de do EMIEP, no sentido de buscar a (re)construção do seu processo de formação, que se encontram em permanente processo de alterações.

\section{REFERÊNCIAS}

ARAUJO, R. M. L.; FRIGOTTO, G. Práticas pedagógicas e ensino integrado. Revista Educação em Questão, v. 52, n. 38, p. 61-80, 2015.

BRASIL. Indissociabilidade ensino-pesquisa-extensão e a Flexibilização curricular: uma visão da extensão / Fórum de Pró-Reitores de Extensão das Universidades Públicos Brasileiras. UFRGS; Brasília: MEC/SESu,2006

. Ministério da Educação. Educação Profissional Técnica de Nível Médio Integrada ao Ensino Médio. Documento Base. 2007. Disponível em: http://portal.mec.gov.br/setec/arquivos/pdf/documento_base.pdf. Acesso em: 30 ago. 2019.

. Lei no 11.892, de 29 de dezembro de 2008. Institui a Rede Federal de Educação Profissional, Científica e Tecnológica, cria os Institutos Federais de Educação, Ciência e Tecnologia, e dá outras providências. Diário Oficial [da República Federativa do Brasil], Brasília, DF, n. 253, p. 1, dez. 2008. Seção 1. 
Ministério da Educação. Um novo modelo em educação profissional e tecnológica. Concepção e Diretrizes. Secretaria de Educação Profissional e Tecnológica. 2010. Disponível em:

http://portal.mec.gov.br/index.php?option=com_docman\&view=download\&alias=6691 -if-concepcaoediretrizes\&category_slug=setembro-2010-pdf\&Itemid=30192. Acesso em: 30 ago. 2019.

Parecer CNE/CEB N. 11/2012. Diretrizes Curriculares Nacionais para a Educação Profissional de Nível Médio. Diário Oficial da União, Brasília, 04 de setembro de 2012, Seção 1, p. 98.2012a.

, Resolução CNE/CEB N. 06/2012. Define Diretrizes Curriculares Nacionais para a Educação Profissional Técnica de Nível Médio. Diário Oficial da União, Brasília, 04 de setembro de 2012.2012b

Constituição da República Federativa do Brasil [recurso eletrônico]. Brasília: Supremo Tribunal Federal, Secretaria de Documentação, 2019. Disponível em: https://www.stf.jus.br/arquivo/cms/legislacaoConstituicao/anexo/CF.pdf. Acesso em: 26 set. 2019.

CIAVATTA, M. A formação integrada: a escola e o trabalho como lugares de memória e de identidade. In: RAMOS, Marise. (Org.); FRIGOTTO, G.; CIAVATTA, Maria (Orgs.). Ensino Médio Integrado: concepção e contradições. São Paulo: Cortez, 2005; pp. 83-105.

FREIRE, P. Extensão ou comunicação? tradução de Rosisca Darcy de Oliveira .7. ed. Rio de Janeiro: Paz e Terra, 1983

IFFar. Plano de Desenvolvimento Institucional (PDI) do Instituto Federal de Educação, Ciência e Tecnologia Farroupilha. 2019.a Disponível em: file:///C:/Users/User/Downloads/PlanodeDesenvolvimento\%20(4)\%20.pdf. Acesso em: 10 set. 2019 .

Resolução n²8/2019 Define as Diretrizes Institucionais da Organização Administrativo-Didático-Pedagógica para a Educação Profissional Técnica de Nível Médio no Instituto Federal Farroupilha. 2019. b. Disponível em: https://www.iffarroupilha.edu.br/regulamentos-elegisla\%C3\%A7\%C3\%B5es/resolu\%C3\%A7\%C3\%B5es/item/14837resolu \%C3\%A7\%C3\%A3o-n\%C2\%BA-028-2019-revoga-aresolu\%C3\%A7\%C3\%A3o-consup-n\%C2\%BA-102-2013-define-as-diretrizesadministrativas-e-curriculares-para-a-organiza\%C3\%A7\%C3\%A3o-did\%C3\%A1ticopedag\%C3\%B3gica-da-educa\%C3\%A7\%C3\%A3o-profissional-t\%C3\%A9cnica-den\%C3\%ADvel-m\%C3\%A9dio-no-iffar. Acesso em: 20 set. 2019.

PACHECO, E. (org). Os Institutos Federais. Uma revolução na educação profissional e tecnológica. Brasília: Fundação Santillana; São Paulo: Moderna, 2011.

RAYS, O. A. Ensino-Pesquisa-Extensão: notas para pensar a indissociabilidade. Revista Cadernos de Educação Especial, n. 21, 2003, p. 71-85. 
RAMOS, M. Ensino médio integrado: ciência, trabalho e cultura na relação entre educação profissional e educação básica. In: MOLL, J. et al. Educação profissional e tecnológica no Brasil contemporâneo: desafios, tensões e possibilidades. Porto Alegre: Artmed, 2010. p. 42-57.

SOBRINHO, S. C. Diretrizes institucionais e a perspectiva da integração curricular no Iffarroupilha. In: ARAÚJO, A. C.; SILVA, C. N. N. Ensino Médio Integrado no Brasil: fundamentos, práticas e desafios. Brasília: Editora IFB, 2017. 